\title{
Introduction to a special issue in honor of Kenneth Arrow
}

\author{
Elizabeth Maggie Penn ${ }^{1}$
}

Received: 24 September 2018 / Accepted: 28 September 2018 / Published online: 9 October 2018 (c) Springer Science+Business Media, LLC, part of Springer Nature 2018

On February 21, 2017, the fields of economics and political science lost a luminary with the passing of Kenneth J. Arrow, one of the most important intellectuals of the 20th century. Arrow's "impossibility theorem" $(1951,1963)$ represents the starting point of modern social choice theory, and the axiomatic method he employed in its presentation and proof represents a cornerstone of the modern theory of measurement. Arrow won the John Bates Clark Medal in 1957. He won the Nobel Memorial Prize in Economic Science in 1972the youngest person to ever receive the prize-for his work on welfare economics and general equilibrium theory. In a career spanning over seventy years Arrow made a staggering number of contributions to social science, including to topics as varied as choice under uncertainty and risk, asymmetric information, the economics of research and development, endogenous growth theory, and climate change.

I first encountered Arrow's work in graduate school, in a course taught by Jeff Banks at Caltech. In the fifteen years that I have been teaching social choice to my own graduate students I continue to be surprised by the force and reach of these classic results, the frequency with which I think "well that's not surprising if you understand Arrow's theorem." Once one learns this material it's impossible not to see it everywhere, and (like so many others, I know) Arrow's contributions have deeply influenced my own work, how I think about science, and how I think about the world. I am pleased and honored to present this special issue in honor of Kenneth Arrow's life and work. The issue contains nine articles, a mix of original research pieces, reflections on Arrow's numerous contributions and their scope, and personal accounts of Arrow himself. Each of the issue's authors have dedicated much of their careers to exploring topics that Arrow pioneered, and the range of topics touched on and methodological approaches taken speaks to the richness of Arrow's agenda.

In Weak rationalizability and Arrovian impossibility theorems for responsive social choice John Duggan explores a collection of problems deriving from an early contribution of Arrow's to choice theory, termed Arrow's choice axiom. Arrow considered the problem of whether and when observed choice behavior could be said to have been derived from an individual maximizing a transitive preference ordering (or to be transitively rationalizable). Arrow's choice axiom lays out a necessary and sufficient condition for choice behavior to satisfy in order to admit a transitive rationalization. Like other work in this vein, Arrow's formulation of the problem assumes a finite set of alternatives, and assumes that choices over every possible subset of alternatives are observable and exist (i.e., at least one element

Elizabeth Maggie Penn

elizabeth.m.penn@gmail.com

1 Emory University, Atlanta, USA 
is chosen from any feasible set). Moreover, without that assumption Arrow's choice axiom is not sufficient for transitive rationalizability. However, the assumption that choice sets be nonempty becomes restrictive when we consider infinite feasible sets that may not be compact; in such cases, nicely behaved preferences may not admit maximal elements. Duggan begins his contribution by extending Arrow's choice axiom to precisely that setting, setting up a necessary and sufficient condition for transitive rationalizability while allowing for empty choice sets from infinite feasible sets. Duggan then moves to the question of whether we can more fully characterize choice behavior satisfying Sen's conditions $\alpha$ or $\gamma$. Sen (1971) proved that these conditions are necessary and sufficient for choice to be rationalized by an acyclic relation. Duggan provides representation theorems for choice functions satisfying $\alpha$ and $\gamma$ alone, characterizing the choice behavior satisfying those weak rationality conditions as proto-rationalizable and pseudo-rationalizable, respectively. The paper concludes with a collection of impossibility results firmly in the Arrovian tradition that significantly weaken both collective rationality (utilizing $\alpha, \gamma$, a new condition termed $\delta^{*}$, and even the total absence of collective rationality), and that weaken previously explored responsiveness conditions, such as May's positive responsiveness (May 1952).

Jon Eguia and Dimitrios Xefetris depart from the standard Arrovian framework to consider a setting of binary group choice and cardinal (and unit comparable) individual utilities in their piece Social welfare with net utilities. Building upon work by Roberts (1980), Moulin (1991), Sen (1970), and others, the authors prove a representation theorem characterizing the class of collective utility functions that satisfy the axioms of anonymity, neutrality, monotonicity, separability, and scale invariance. These axioms ensure that collective preferences depend solely on the set of net utilities that the pair of alternatives generate; that the social value of one alternative relative to another is increasing in individuals' net utilities; that social welfare is additively separable in (some function of) individuals' net utilities; and that the social ranking of alternatives is unaffected by the choice of units in which utility levels are measured. They prove that, letting $v_{i}$ be individual $i$ 's net utility for alternative A relative to alternative B, these axioms characterize a "net collective utility function" of the form

$$
\sum_{i \in N} \operatorname{sgn}\left(v_{i}\right)\left|v_{i}\right|^{\rho}
$$

where $\rho$ is a positive constant. $\rho$ can be interpreted as a normative parameter capturing the importance of intensity of preference to social welfare. When $\rho=0$, then this rule reduces to majority rule between the two alternatives, and intensity of preference is irrelevant. As $\rho \rightarrow \infty$, all that matters is intensity of preference, and the socially chosen alternative is the alternative chosen by the individual with the greatest utility difference between the two alternatives. Thus, the result speaks to axiomatic treatments of majority rule (May 1952), utilitarianism (Maskin 1978), and the difference principle (Rawls 1971).

In an article dedicated to Arrow, de Mouzon, Laurent, Le Breton, and Lepelley examine alternatives to the current system of voting within the electoral college. Their Exploring the effects of national and regional popular vote interstate compact on a toy symmetric version of the Electoral College: an electoral engineering perspective takes a rigorous approach to studying the implications-in terms of within-state and national welfare, power differentials, and the likelihood of an "election inversion" whereby the winner of the popular vote loses-of several well-known proposals to modify how electoral votes are cast by states. Presently, the National Popular Vote Interstate Compact (NPV) has been enacted into law by 11 states that have agreed to award all of their electoral votes to the 
candidate receiving the plurality of popular votes. However, the agreement goes into effect among the participating states only once they collectively represent an absolute majority of Electoral College votes. Here the authors consider two variants of the NPV proposal in which the compact is implemented immediately among participating states. The first is termed the National Modified Popular Vote, or NMPV—-see Brams and Kilgour (2013) in which participating states cast their votes for the national popular winner. The second is termed the Regional Modified Popular Vote (RMPV), in which participating states cast their votes for the popular winner of their bloc's own (amalgamated) vote. Utilizing common assumptions about vote distributions across states, the authors numerically derive the optimally sized interstate compact for the RMPV - the ideal number of compact participants to maximize their own Banzhaf power. The authors also demonstrate that while the RMPV compact imposes a negative externality on non-compact states, the NMPV imposes a positive externality on non-compact states, and, surprisingly, convergence to the popular vote may be obtained for relatively small interstate compact sizes.

While these first three articles present positive results (representation theorems and results concerning the evaluation of voting systems), the remainder of this issue's articles are more philosophical in nature. Sean Ingham, in Why Arrow's theorem matters for political theory even if preference cycles never occur and Nicholas Miller, in Reflections on Arrow's theorem and voting rules, both explore the claim, inspired in part by William Riker's Liberalism against populism (Riker 1982), that Arrow's theorem presents serious challenges to the possibility and scope of democratically legitimate governments. Ingham responds to Riker's critics, who argue that Arrow's theorem has little normative bite because majority preference cycles rarely occur in practice. These critics argue that concerns about the existence of a "popular will" are unfounded. Ingham argues that when considering the application of the theorem to populist principles of democratic legitimacy, the assumption of unrestricted domain is justified irrespective of the preferences citizens are likely to have. He makes a case for the importance of (application specific) methodological rules for debating the assumptions of Arrow's theorem. Criticisms of unrestricted domain may be justified if countering an attempt to use Arrow's theorem to argue that chaotic majority outcomes are empirically likely. However, without a philosophical justification for a restricted domain, assuming away cycles as a defense of populism looks like an ad hoc attempt to save a principle from counterexample. This is particularly true when considering that, in Ingham's words, “...it is precisely under conditions of diversity and disagreement that democracy is thought to have its unique claim to legitimacy."

Miller takes a more pragmatic approach to the problem. He counters the claim that "democracy is impossible" with the more muted claim that "Arrow's theorem means that all real-world voting rules are problematic in two quite specific ways-namely, they are neither 'strategyproof' nor 'spoilerproof.' But at the same time, many voting rules are problematic in other ways that cannot be blamed on Arrow's theorem." He argues-both theoretically and anecdotally-for the case of majority rule, which can circumvent some of the problems that plague other systems. While that system is subject to the possibility of cyclic majorities, Miller is not convinced that this should be a real-world concern.

The next two papers-Wulf Gaertner's Kenneth Arrow's impossibility theorem stretching to other fields and Donald Saari's Arrow, and unexpected consequences of his theorem-both focus on applications of Arrow's theorem to domains far outside the realm of welfare economics and voting theory. Gaertner begins by focusing on the fields of engineering design and philosophy of science. Thomas Kuhn famously argued that in order to adjudicate between competing scientific theories, one should weigh the five criteria of accuracy, consistency, scope, simplicity and fruitfulness (Kuhn 1962, 1977). Reliance on 
multiple, possibly contradictory, criteria for evaluation —and the inherent impossibilities suggested by Arrow's theorem-led to Kuhn's ultimate conviction that a neutral algorithm for theory choice does not exist and, consequently, some individual subjectivity must enter into any evaluation. Okasha (2011) has interpreted Kuhn's problem as one of social choice, and Gaertner notes that the scholarly debate following Okasha's article is reminiscent of the debate in social choice following publication of Social Choice and Individual Values, and debates concerning optimal design decisions in engineering. In each of these disparate fields arguments were proposed to circumvent Arrovian-style impossibilities, including giving up unrestricted domain, embracing dictatorial rules, and violating independence via Borda-type procedures.

Saari's engaging piece begins with a lovely personal remembrance of Arrow. Saari broadens the scope of Arrow's theorem to explain topics as varied as Bernie Madoff, the Christmas Day underwear bomber, apportionment paradoxes, engineering puzzles in nanotechnology, and the mystery of dark matter (to name a few)! Saari argues that the conceptual link between each of these phenomena is that perverse outcomes are a consequence of a reductionist approach to problem-solving, whereby complexity is reduced by focusing on a problem's smaller component parts. When problems are "siloed" from each other (as is necessitated by Arrow's axiom of IIA) valuable connecting information is lost, and unexpected outcomes can ensue. Saari makes the case for recovering and utilizing this connecting information by adopting a summation approach - the Borda count - that utilizes but "massages" IIA information to create desirable outcomes.

John Patty and I take the opposite side of the argument to make the case for Arrow's much maligned IIA in our A defense of Arrow's independence of irrelevant alternatives. Building upon arguments in our 2014 book (Patty and Penn 2014), we begin by responding to a number of well-known criticisms of IIA and presenting several simple results concerning the IIA axiom. These results show that IIA, a demanding condition, follows from a number of conditions that would appear to be far weaker, such as allowing the rule to respond to cardinal differences and relaxing the assumption of binary independence. We also show that IIA in fact implies transitivity (and by extension, dictator) when we require collective preference to pick a clear winner. Our paper argues that the appeal of the axiom is best understood by stepping back from elections and preference aggregation-settings in which we agree with many of IIA's critics. Violations of IIA are more troubling to us in contexts where many alternatives are considered simultaneously, good information is available about the ranking of each alternative with respect to each criterion being aggregated, final decisions can be scrutinized and revisited, and/or the correlation between how the various criteria rank alternatives is low. A mass election is precisely a decision-making scenario that satisfies none of these conditions. Our main concern lies in the fact that a violation of IIA implies that the measurement of the alternatives in set $A$ is not identified without information about alternatives outside of $A$. Consequently, if an aggregation rule violates IIA, then situations exist in which providing evaluative information about a relevant subset of alternatives is insufficient to return an evaluation of those alternatives. This is problematic: from a practical standpoint, evaluative information may be unavailable for all of the alternatives. And when such information is gathered, it may change the relative ranking of other alternatives whose measures were unchanged. Maintaining IIA (and a procedure's consequent susceptibility to an Arrovian paradox) we conclude with a notion of legitimate collective choice that includes a richer justification of chosen alternatives.

Finally, Kenneth Shepsle provides a personal account of time spent with Arrow and revisits Arrow's work on risk-bearing in Remembering Kenneth Arrow: discount rates. In their 1970 paper, Arrow and economist Robert Lind proved an important theorem on 
risky public projects, showing that in certain environments the social cost of risk disappears as the size of the population tends to infinity, regardless of the risk preferences of individuals (Arrow and Lind 1970). A consequence of the Arrow-Lind theorem is that, for large populations, certain public projects can be evaluated solely on the basis of their net flow of benefits discounted for time, and not for risk. Shepsle argues that for certain important types of public investments the theorem's conditions do not hold; these include public goods whose benefits are neither divisible nor appropriable (and thus, goods for which risk can't be widely spread across the project's beneficiaries). An example is a flood wall. If the wall breaks, each individual bears the full brunt of the failure. Thus, Shepsle argues, it is not clear that present values of pure public goods can avoid discounting for risk. Shepsle's note asks us to remember Arrow's contributions to uncertainty and risk, and to reexplore their relevance in a present-day world characterized by intertemporal instability.

It is my hope that readers of this special issue will enjoy and learn from these papers, and find them a testament to the depth, scope, and influence of Kenneth Arrow's writings. I speak for myself and each of this issue's contributors by saying that it has been a privilege to honor an individual whose scholarship has so profoundly influenced our own.

\section{References}

Arrow, K. J. (1951). Social choice and individual values. New York, NY: Wiley.

Arrow, K. J. (1963). Social choice and individual values (2nd ed.). New York, NY: Wiley.

Arrow, K., \& Lind, R. (1970). Uncertainty and the evaluation of public investment decisions. American Economic Review, 60(3), 364-378.

Brams, S. J., \& Kilgour, D. M. (2013). Voting power under a modified popular vote plan in US presidential elections. Mimeo, New York University.

de Mouzon, O., Laurent, T., Le Breton, M., \& Lepelley, D. (2018). Exploring the effects of national and regional popular vote interstate compact on a toy symmetric version of the electoral college: An electoral engineering perspective. Public Choice. https://doi.org/10.1007/s11127-018-0576-7.

Duggan, J. (2018). Weak rationalizability and Arrovian impossibility theorems for responsive social choice. Public Choice. https://doi.org/10.1007/s11127-018-0528-2.

Eguia, Jon X., \& Xefteris, D. (2018). Social welfare with net utilities. Public Choice. https://doi. org/10.1007/s11127-018-0527-3.

Gaertner, W. (2018). Kenneth Arrow's impossibility theorem stretching to other fields. Public Choice. https ://doi.org/10.1007/s11127-018-0503-y.

Ingham, S. (2018). Why Arrow's theorem matters for political theory even if preference cycles never occur. Public Choice. https://doi.org/10.1007/s11127-018-0521-9.

Kuhn, T. S. (1962). The structure of scientific revolutions. Chicago: University of Chicago Press.

Kuhn, T. S. (1977). Objectivity, value judgment, and theory choice. In T. S. Kuhn (Ed.), The essential tension-Selected studies in scientific tradition and change (pp. 320-339). Chicago: University of Chicago Press.

Maskin, E. (1978). A theorem on utilitarianism. The Review of Economic Studies, 45(1), 93-96.

May, K. O. (1952). A set of independent necessary and sufficient conditions for simple majority decision. Econometrica, 20(4), 680-684.

Miller, N. R. (2018). Reflections on Arrow's theorem and voting rules. Public Choice. https://doi. org/10.1007/s11127-018-0524-6.

Moulin, H. (1991). Axioms of cooperative decision making. New York, NY: Cambridge University Press.

Okasha, S. (2011). Theory choice and social choice: Kuhn versus Arrow. Mind, 120(477), 83-115.

Patty, J. W., \& Penn, E. M. (2014). Social choice and legitimacy: The possibilities of impossibility. New York, NY: Cambridge University Press.

Patty, J. W., \& Penn, E. M. (2018). A defense of Arrow's independence of irrelevant alternatives. Public Choice. https://doi.org/10.1007/s11127-018-0604-7.

Rawls, J. (1971). A theory of Justice. New York: Oxford University Press.

Riker, W. H. (1982). Liberalism against populism. San Francisco, CA: W.H. Freeman \& Company. 
Roberts, K. W. S. (1980). Interpersonal comparability and social choice theory. The Review of Economic Studies, 47, 421-439.

Saari, D. G. (2018). Arrow, and unexpected consequences of his theorem. Public Choice. https://doi. org/10.1007/s11127-018-0531-7.

Sen, A. (1970). Interpersonal aggregation and partial comparability. Econometrica: Journal of the Econometric Society, 38, 393-409.

Sen, A. K. (1971). Choice functions and revealed preference. The Review of Economic Studies, 38(3), 307-317.

Shepsle, K. A. (2018). Remembering Kenneth Arrow: discount rates. Public Choice. https://doi. org/10.1007/s11127-018-0520-x. 